\title{
A Review Paper on Adoption Behavior of Vegetable Growers towards Pest Management Practices in Bulandshahr (U.P.), India
}

\author{
R.V. Singh ${ }^{1}$, Meenakshi Malik ${ }^{1 *}$, A.K. Kanojia ${ }^{1}$ and Avinash Singode $^{2}$ \\ ${ }^{1}$ ICAR-National Research Centre for Integrated Pest Management, India \\ ${ }^{2}$ ICAR-Indian Institute of Millets Research, Hyderabad \\ *Corresponding author
}

\section{Keywords \\ Adoption, Pest management, IPM, Vegetable crops, Bulandshahr, farmers, IPM Approach}

\section{Article Info}

Accepted: 10 June 2018 Available Online: 10 July 2018

\section{A B S T R A C T}

Pest control practices in the vegetable crops have been heavily dominated by the routine use of broad-spectrum insecticides to control pests. Concerns have emerged about the adverse consequences of over use of pesticide. These consequences include short and longterm health hazards, contamination and environmental degradation. To minimize the pest losses farmers heavily depend on the chemical pesticides and accessing pest management information from the pesticide dealers due to weak state extension support system. Vegetable production plays a crucial role in agriculture by providing food, nutritional and economic security to the people of with higher returns per unit area to the producers. The study was conducted with objective to find out the adoption behavior of farmers towards pest management in western region of Uttar Pradesh. The studied adoption level of pest management practices in study area by following proportionate random sampling method 100 vegetable growers were selected and primary data was collected though personal interview method. Findings revealed that majority of the respondents had medium level of adoption of IPM practices while equal per cent of respondents $(20 \%)$ had high and low level of adoption, respectively. With regard to cultural practices, majority of the farmers had adopted the practice of transplanting of recommended number of seedling. As mechanical control measures, the raised bed nursery had adopted by majority farmers. Among the cultural, mechanical, biological and chemical measures of Integrated Pest Management, respondents mainly followed cultural and mechanical methods for pest management of cauliflower crop. Utilization of locally available resources and promotion of the Farmers Participatory Approach by incorporating the vegetable growers' indigenous wisdom about the Bio-pesticides and the natural enemies of the pests of the vegetables in the sphere of IPM techniques of the vegetables grown by the farmers is very essential in this State. 


\section{Introduction}

Integrated Pest Management (IPM) as one of the tools that has come up in recent years for reducing damages caused by pests without harming the environment. In the world, pests and diseases is one of the major rising problems in the agricultural commodity and use of pesticides against these problems has been leaving a negative effect on human health and whole ecosystem. With the overwhelmingly increased awareness of the growers, consumers, traders and scientific communities in developed and developing countries as well on non-chemical agriculture, enormous number of efforts have been made to look alternatives to the chemical pesticides in recent days through either judiciary use of chemicals or through the use of bio-products. IPM practices also helps in providing a safer environment and reducing or minimizing the risks to human health. Pesticides are used only after monitoring indicates they are needed according to established guidelines and treatments are made with the goal of removing only the target organism. The selected pest control materials are applied in a way that reduces the risks to human health, beneficial and non-target organisms and the environment. Using a combination of methods that work better together than separately is the most effective, long-term way to manage pests.

The studied adoption level of pest management practices in Bulandshahr District of Uttar Pradesh by following proportionate random sampling method of 100 vegetable growers. The primary data were collected though personal interview method. In this study adoption level refers to the level of adoption of recommended pest management practices of vegetable crops by the respondents. Pest management practices included in the package of practices in vegetable cultivation were used for measuring this adoption. The participatory extension approach is used in the research work for extension of IPM technologies in the western U.P. The pro-active role of state extension agencies such as KVKs and State Department Agriculture for information delivery and input supply certainly will motivate the farmers for adoption of IPM. Therefore, accelerating the adoption of IPM in vegetable crops by involving the public and private extension with farmer for extending the promising vegetable IPM in participatory mode is needed on priority. The adoption of IPM practices by educating and visualizing the importance of IPM practices among the arming community is also an effective way. National Research Centre for IPM has been always emphasizing to identify the barriers and constraints that directly relate to the low adoption of IPM technologies in vegetable crops. The project will help in enhancing the knowledge, awareness and adoption of promising IPM practices through innovative extension tools and the capacity building and scaling up programmes for IPM stakeholders for better technology transfer and adoption of IPM, in so doing, effectively help sustain vegetable production.

\section{Related work}

Singh et al., (2016) studied the socio economic condition of medium farmers and found that they are better than the farmers of the other category because of monthly expenditure, resource rich condition on family structure, size of land holding and education level. The specific objective of the study was to know the socio-economic profile of the vegetable growers in Meerut District of Uttar Pradesh and to estimate the cost and return and constraints related to production and marketing. Vegetable production is a crucial part in agriculture as it provides food, nutritional and economic security to the people of with higher returns per unit area to 
the producers. The overall cost of the Brinjal, cabbage and tomato crop was Rs. 119686.64, Rs.80762.04 and Rs. 85453.36. And among different categories it was Rs. 117125.98, 120640.73 and 121109.07 for brinjal on marginal, small and medium size of farms respectively, indicating there by its direct relationship with the size of farms and net returns per hectare amounted to be Rs. 147517.93, Rs. 150197.52 and Rs. 164000.02 per hectare respectively. For cabbage it was Rs. 79904.51, 81850.14 and 80067.26 and net returns estimated to Rs. 126932.74, Rs.129349.86 and 134895.49 and average per hectare and tomato was Rs. 79759.80, 88391.89 and 87482.38 on the respective size of holding and net returns per hectare amounted to be Rs. 246018, 252008 and 266390 rupees on marginal, small and medium farms, respectively. Most of the vegetable growers were faced problems of lack of storage facility, high price of plant protection chemical and high incidence of diseases/insect in HYVs with 90.00, 88.00 and 79.00 percent respectively.

Ram et al., (2012) studied adoption level of IPM practices in Imphal East District of Manipur by following proportionate random sampling method of 100 vegetable growers by collecting the primary data though personal interview method. The findings revealed that the majority of the respondents had medium level of adoption of IPM practices while equal per cent of respondents $(20 \%)$ had high and low level of adoption, respectively. Majority of the farmers had adopted the practice of transplanting of recommended number of seedling per hill, with regard to cultural practices. As mechanical control measures, the use of bamboo-cage-cum-perchers to control pest in cole crops had adopted by 70 percent farmers. The use of neem products/neem-based pesticide was also noticed in case of 40 percent farmers in respect to biological control measures. The application of chemical control measures was relatively not significant among the farmers. The respondents mainly followed cultural and mechanical methods for pest management of cabbage and cauliflower crops among the various methods of integrated pest management. Promotion of the Farmers Participatory Approach by incorporating the vegetable growers and utilization of locally available, indigenous wisdom about the biopesticides and the natural enemies of the pests of the vegetables in the sphere of IPM techniques of the vegetables is very important in this State.

Singh et al., (2003) included fifteen recommended practices in the package of practices in vegetable cultivation for measuring the adoption of IPM. The study revealed that there is an urgent need to increase the productivity of vegetable in order to provide nutritional security to increasing population of India. The findings of this study highlighted that about 85 percent of the vegetable growers had low or medium adoption of commercial cabbage cultivation practices meaning there by medium adopters were more energetic, knowledgeable, dynamic and having more interest in adopting modern vegetable technologies. Due to its proximity to National Capital Territory of Delhi, Ghaziabad has a great potential for commercial vegetable cultivation. Hence, the study was carried out in eight blocks of this district.

Bond et al., (2009) employed the Theory of Planned Behavior (TPB) to gauge farmer's attitude, subjective norms and perceived behavioral control towards pesticides in combination with Participatory Rural Appraisal (PRA) tools to adapt an extension program promoting IPM in Jharkhand. Farmers had a strong behavioral intention and favorable attitude to apply pesticide in the coming season. The success of extension program is likely to depend more on the 
involvement of women and marginal farmers in activities and dispelling myths of pesticide function. The farmers have an intention towards pesticide use was the key learning from the study. The attitude is the most important factor for influencing the behavioral intention and the applicability of the TPB to a development extension context. Subsequently, the main goal behind the project was to promote safe vegetable production and to initiate Integrated Pest Management (IPM) research and development.

Prajapati et al., (2013) demonstrated integrated pest and disease management (IPDM) strategies blended with proven technologies including bio-agents on rice variety, Pusa Sugandha-4 in the Mid Western Plain Zone of U.P. at farmers field with the aim to reduce the production cost and pesticides load over the crop. All the activities of demonstration were carried out in close coordination with scientists and farmers as well. It was found that, in spite of using pesticides in general, lower incidence of insects and diseases along with higher numbers of natural enemies and yield were recorded in all the IPDM adopted fields as compared to farmers practices (FP). The average yield of IPDM fields was higher by $10.70 \mathrm{q} / \mathrm{h}$ coupled with higher number of tillers/hill (12.72), grains per panicle (121) and higher test weight $(25.10 \mathrm{~g})$. Superiority of IPDM package was also evidenced by economic analysis as cost benefit ratio of 1:2.90 and 1:2.37 was obtained in IPDM and farmers practices, respectively.

Fliert et al., (1995) took a major ingenious effort to devise a new type of farmer training on IPM, made by Indonesia by the so-called National Program since 1989. The Indonesia National IPM program applied a completely different, eccentric extension approach enabling farmers to follow IPM principles as indicated. The main principles of Non-Formal
Education were employed to design the Farmers Field school as a basic model for IPM training. The learning through experience and experimentation of real filed problems was emphasized by this model. After a cadre of competent IPM field trainers were trained, thousands of successful IPM farmer field schools were conducted, outside the regular activities of the national extension service program.

Desai et al., (2013) collected data from Sabarkantha district of Gujarat through well structured interview schedule and personal interview and found that majority (79.27 percent) of the respondents had medium to high level of overall adoption of market intelligence. More than half of the respondents had adopted grading, transportation and marketing channel practices, while demand, source to know selling price and packaging practices were less adopted by the respondents. In the adoption of market intelligence, the independent variables viz., education, land holding, annual income and level of knowledge of the summer cabbage growers established in a positive way and have highly significant association. The highest price during the summer season is the driving force within the farmers of Sabarkantha district of Gujarat state to cultivate the cabbage as a summer crop, due to the availability of potential and high temperature resistant varieties.

Venkataramalu et al., (2004) conducted a study in Guntur district (Andhra Pradesh) with the sample size of 120 farmers through a teacher made knowledge test, developed to measure the knowledge level of farmers about improved cultivation practices. The findings revealed that majority of the respondents had medium level of knowledge and a considerable percentage of respondents were educated till primary school. Majority 
(74.17\%) of the respondents possessed TV sets, among these 55.83 per cent of respondents were regular viewers of news.

Venkataramulu et al., (2010) conducted a study in Guntur district (Andhra Pradesh) with the sample size of 120 farmers. The method used by Sengupta (1967) was followed for measuring adoption by the farmers in respect of the chilli cultivation practices. Majority of the respondents $(68.33 \%)$ belonged to medium adoption category and also indicated that pesticides and fungicides were applied more than recommended dosage by 98.33 per cent of respondents.

Singh et al., (2010) included fifteen practices recommended in the package of practices in vegetable cultivation for measuring the adoption of modern vegetables technologies. This study was conducted in the eight blocks of district Ghaziabad. In this study adoption level refers to the level of adoption of recommended cultivation practices of potato by the respondents. It concluded that about 82 percent of the vegetable growers had low or medium adoption of commercial potato cultivation practices and means that medium adopters have more interest in adoption of new and beneficial methods.

Ahuja et al. (2012) implemented Integrated Pest and Disease Management programme in irrigated cauliflower crop which led to reduction of $50-60 \%$ in the number of conventional pesticide sprays. The use of less or required pesticide application was reinforced by enemies resulting in sustainable and stable pest control regime. The safer biorational pesticides, insect growth regulators and cultural methods of pest management as introduced in the IPM programme were well received by the farmers in farmers participatory trainings (FPT). The module was able to drag the cost of crop protection down by 45 percent resulting in higher benefit-cost ratio. The education of farmers about the right choice of pesticides, proper time and dose of application, pest monitoring and application of pesticides based on action threshold was revealed by the post implementation evaluation of the IPM programme. Increase in participation of women in the IPM programme was ensured by educating them about the mechanical management of S. litura.

Ying et al., (2003) studied the development of IPM (from 1950 to the early 1970s, 1974 to 1982 and from 1983 to 2003), IPM organizational structure, IPM research and practice (pest monitoring and forecasting, cultural control, biological control and pest resistance) and examples of successful IPM application (rice, wheat and maize) in China.

Perumal et al., (2004) studied to identify the constraints faced by the farmers in the adoption of IPM practices and to suggest appropriate corrective measures to make farming a viable and profitable enterprise. The major findings on the constraints faced in the adoption of IPM technologies among IPM and Non-IPM farmers were analyzed and found that the production of rice mainly depends upon the management of pests and diseases, which takes a major share in the total production cost. Integrated pest management (IPM) is the eco-friendly solution to overcome the pest management problems.

Rao et al., (1983) took up a study in five districts (Mandya, Mysore, Shimoga, Hassan and Bangalore regions) of Karnataka, India. The impact of farmer's field schools (FFSs) on knowledge measured the attitude of farmers and extension personnel in respect to IPM practices in rice farming. The respondents consisted of 60 trained and 60 untrained rice farmers and 60 trained and 60 untrained extension personnel. The results 
revealed that $53 \%$ of the trained farmers and $48 \%$ of the trained extension personnel had a high level knowledge on IPM practices in rice cultivation. It also revealed that $43 \%$ of the trained farmers and $37 \%$ of the trained extension personnel had more favorable attitude towards IPM practices in rice cultivation. Further, it also revealed that $36 \%$ of the farmers and $42 \%$ of the extension personnel had a low level of knowledge regarding IPM practices for rice, whereas $33 \%$ of the farmers and $46 \%$ of the extension personnel had a less favorable attitude towards IPM in rice cultivation.

Peshin et al., (2009) selected a sample of 150 farmers (135 of which were trained in integrated pest management or IPM and 15 were untrained) in Ludhiana district, Punjab to study the extent and level of adoption of IPM practices in rice crop. There was hardly any difference in the adoption of different cultural practices between IPM and non-IPM farmers, but the resistant cultivars were adopted by the IPM farmers in a large scale. IPM farmers had applied lesser number of pesticide sprays as compared to non-IPM farmers. Ten percent of the IPM-trained farmers did not apply any insecticide. The employment of farmers was found necessary to have the desired impact of IPM, which was lacking in the case in all villages.

Singh et al., (2007) examined pesticide usage pattern and adoption of integrated pest management (IPM) practices in rice, vegetables and cotton. Estimated values of farmers' willingness to pay for pesticide hazard reduction indicated that a marker exists for environmentally friendly pesticides in the study areas.

Singh et al., (2008) studied adoption of Integrated Pest Management (IPM) practices on paddy in Haryana and assessed the impact of key socio-economic and institutional factors on adoption. A survey was conducted in 2003-04 on 83 farmers cultivating paddy in the Karnal and Kaithal districts of Haryana. The study concluded that technology awareness through formal crop-specific IPM training provided by farmers' field schools was extremely important for wider adoption of IPM in the study area and has found mixed evidence about the relationship between farmsize and adoption of IPM practices. In the case of paddy, a negative relationship was observed.

Lal et al., (2008) conducted an experiment in Bhagalpur, Bihar to determine the constraints in adoption of IPM in rice cultivation. The overall percentage regarding the constraints pertaining to technology was 67.80 , constraints pertaining to extension were 73.33 and constraints pertaining to service, supply and marketing was 70.25 and constraints pertaining to transfer of technology were 66.85 in the adoption of IPM in rice cultivation.

Mariyono et al., (2008) studied Integrated Pest Management (IPM) technology disseminated since 1989 in Indonesia to cut down pesticide use, but the adoption and diffusion of the technology were still debated. This study aimed to estimate the models of demand for pesticides and to analyze the impact of IPM technology on pesticide use. There was an indication that IPM technology has been adopted by farmers. This is evidence that the IPM programme in Indonesia was successful in this area.

Sharifi et al., (2008) developed integrated pest management (IPM) as one of sustainable Agricultural development components, based on synergy of empowering farmers, environmental friendly technology and integrated farm management. Effective IPM extension needs identification and analysis of related principal components with aim to 
policy making and planning by farmers participation. The statistical population included 1145 of rice farmers. A sample of 90 farmers was selected by the use of 31 proportional random sampling methods. The result of factor analysis showed that three components were extracted of IPM practices. The first factor called the optimal cultivation practices that explained $26 \%$ of the total variance and others were biological practices and physical-mechanical practices.

Mohapatra et al., (2009) adopted Indigenous pest control practices by locations in Tamil Nadu, India and studied the efficacy of the most popular practices (including the application of plant extracts and organic amendments) which were evaluated against pests of rice, groundnut, pulses, vegetables and stored grains under field and laboratory conditions. These practices were effective against the pests.

In conclusion, the findings of this research work highlighted that about 85 percent of the vegetable growers had low or medium adoption of commercial cabbage cultivation practices meaning there by medium adopters were more energetic, knowledgeable and dynamic having more interest in adopting modern vegetable technologies. Findings revealed that majority of the respondents had medium level of adoption of IPM practices while equal percent of respondents $(20 \%)$ had high and low level of adoption, respectively. With regard to cultural practices, majority of the farmers had adopted the practice of transplanting of recommended number of seedling per hill. As mechanical control measures, the use of bamboo-cage-cumperchers to control pest in cole crops had adopted by 70 per cent farmers. In respect to biological control measures, use of neem products/neem-based pesticide was also noticed in case of 40 per cent farmers. Application of chemical control measures was insignificant among the farmers. Among the cultural, mechanical, biological and chemical measures of integrated pest management, respondents mainly followed cultural and mechanical methods for management pest of cabbage and cauliflower crops. Utilization of locally available resources and promotion of the Farmers Participatory Approach by incorporating the vegetable growers' indigenous wisdom about the Bio-pesticides and the natural enemies of the pests of the vegetables in the sphere of IPM techniques of the vegetables grown by the farmers is very essential in this State. Farmers had a strong behavioral intention and favorable attitudes, subjective norm and perceived behavioral control to apply pesticide in the coming season. The extension program is likely to be more successful if it dispels myths of pesticide function and includes women and marginal farmers in activities. The key learning's from the study are that farmers have a favorable intention towards pesticide use; attitude was the most important factor influencing behavioral intention; a development extension context. Subsequently, Integrated Pest Management (IPM) research and development need to promote in wide area for safe vegetable production.

\section{References}

Norton et al. (2005). The Need for CostEffective Design and Diffusion of IPM edited in Globalizing Integrated Pest Management- A Participatory Research Process, Blackwell Publishing, USA.

Norton (1976). Analysis of decision making in crop protection, Agro-Ecosystems, Vol. 03, Pp. 27-44.

Kogan et al., (1999). Applications of ecology for integrated pest management. In: Huffaker CB, Gutierrez AP, editors. Ecological Entomology. New York. Pp. 681-736.

Perrings et al., (2005). How to manage biological invasions under globalization. Trends Ecol Evolution. 
Vol. 20(5), Pp. 212-215.

Gregory et al., (2009). Integrating pests and pathogens into the climate change/food security debate. J Exp Bot. Vol. 60(10), Pp. 2827-2838.

Ehler et al., (2006). Integrated pest management (IPM): Definition, historical development and implementation and the other IPM. Pest Management Science. Vol. 62(9), Pp.787-789.

Singh et al., (2016). Economic Analysis of Vegetable Production in Meerut District of Uttar Pradesh. International Journal of Tropical Agriculture. Vol. 34(3).

Ram et al., (2012). Adoption Level of IPM Practices in Cabbage and Cauliflower growers of Manipur. Indian Res. J. Ext. Edu. Vol. 12(2).

Singh et al., (2003). Adoption Behaviour of Commercial Vegetable Growers in District Ghaziabad (UP).

Bond et al., (2009). Understanding farmers pesticide use in Jharkhand India. Extension Farming Systems Journal. Vol. 5. Pp. 53-62.

Prajapati et al., (2013). Evaluation of Integrated Pest and Diseases Management (IPDM) Package on Basmati/Aromatic Rice. African Journal of Agricultural Research. Vol. 8(41), Pp. 5116-5121.

Fliert et al., (1995). Searching For Strategies to Replicate a Successful Extension Approach: Training of IPM Trainers in Indonesia. European Journal of Agricultural Education and Extension. Vol. 1(4), Pp. 41-63.

Desai et al., (2013). Extent of Adoption of the Market Intelligence among the Summer Cabbage Growers. Gujarat Journal of Extension Education. Vol. 24(9).

Venkataramalu et al., (2004). Knowledge of Farmers in Chilli Production Technologies in Guntur District of
Andhra Pradesh. Karnataka J. Agric. Sci. Vol. 17(4), Pp. 747-751

Venkataramulu et al., (2010). Adoption of improved cultivation practices among chilli growers. Karnataka J. Agric. Sci. Vol. 22(5), Pp. 722-725.

Singh et al., (2010). Adoption Behaviour of Commercial Potato Growers in District Ghaziabad (Uttar Pradesh). Indian Res. J. Ext. Edu. Vol. 10 (3).

Ahuja et al., (2012). Development of Farmerled Integrated Management of Major Pests of Cauliflower Cultivated in Rainy Season in India. Journal of Agricultural Science. Vol. 4(2).

Ying et al., (2003). Integrated Pest management in China. Integrated Pest Management in Global Arena. CABI Publishers. Pp. 197-207.

Perumal et al., (2004). Constraints encountered in the adoption of IPM technologies. Karnataka Journal of Agricultural Sciences. Vol. 17(4), Pp. 741-746.

Rao et al., (1983) Proceedings of National Seminar on Crop Losses due to Insect Pests. Indian J. Entomology. (Special issue), Vol. I-II, Hyderabad.

Peshin et al., (2009) Integrated Pest Management: A Global Overview of History, Programs and Adoption. In: Peshin R., Dhawan A.K. (eds) Integrated Pest Management: Innovation-Development Process. Springer, Dordrecht.

Singh et al., (2007). Adoption of integrated pest management in Cotton and Paddy. Agril. Econ. Res. Rev. Vol. 21(2), Pp. 221-226.

Singh et al., (2008). Adoption of Integrated Pest Management Practices in Paddy and Cotton: A Case Study in Haryana and Punjab. Agricultural Economics Research. Vol. 21, Pp. 221-226.

Lal et al., (2008). Soil Degradation as a Reason for Inadequate Human 
Nutrition. Volume 1(1), Pp. 45-57.

Mariyono et al., (2008). The Impact of Integrated Pest Management Technology on Insecticide use in Soybean Farming in Java, Indonesia: Two Models of Demand for Insecticides- Joko Mariyono. Asian Journal of Agriculture and Development.

Sharifi et al., (2008). Studying Integrated
Pest Management (IPM) Rice farming Practices in Marvdasht County, Iran: A Baseline Survey. American-Eurasian Journal of Sustainable Agriculture. Vol. 2, Pp. 158-164.

Mohapatra et al., (2009). Tribal Pest Control Practices of Tamil Nadu for Sustainable Agriculture. Indian Journal of Traditional Knowledge. Vol. 8(2), Pp. 218-224.

\section{How to cite this article:}

Singh, R.V., Meenakshi Malik, A.K. Kanojia and Avinash Singode. 2018. A Review Paper on Adoption Behavior of Vegetable Growers towards Pest Management Practices in Bulandshahr (U.P.), India. Int.J.Curr.Microbiol.App.Sci. 7(07): 1364-1372. doi: https://doi.org/10.20546/ijcmas.2018.707.162 